\title{
The Contribution of Local and Transport Processes to Phytoplankton Biomass Variability Over Different Timescales in the Upper James River, Virginia
}

Qubin Qin

Virginia Institute of Marine Science, qubin@vims.edu

Jian Shen

Virginia Institute of Marine Science, shen@vims.edu

Follow this and additional works at: https://scholarworks.wm.edu/articles

Part of the Environmental Monitoring Commons, and the Population Biology Commons

\section{Recommended Citation}

Qin, Qubin and Shen, Jian, "The Contribution of Local and Transport Processes to Phytoplankton Biomass Variability Over Different Timescales in the Upper James River, Virginia" (2018). Articles. 73. https://scholarworks.wm.edu/articles/73 
The contribution of local and transport processes to phytoplankton biomass variability over different timescales in the Upper James River, Virginia

$5 \quad *$ Corresponding Author:

6 Qubin Qin

$7 \quad$ Virginia Institute of Marine Science

8 College of William and Mary

9 Gloucester Point, VA 23062

10 Email: qubin@vims.edu

11 Phone: (804) 684-7670 
The contribution of local and transport processes to phytoplankton biomass variability over different timescales in the Upper James River, Virginia

\author{
Qubin Qin* and Jian Shen
}

Virginia Institute of Marine Science, College of William and Mary,

Gloucester Point, VA, 23062, USA

\begin{abstract}
Although both local processes (photosynthesis, respiration, grazing, and

16 settling), and transport processes (advective transport and diffusive transport)

17 significantly affect local phytoplankton dynamics, it is difficult to separate their

18 contributions and to investigate the relative importance of each process to the local

19 variability of phytoplankton biomass over different timescales. A method of using the

20 transport rate is introduced to quantify the contribution of transport processes. By

21 combining the time-varying transport rate and high-frequency observed chlorophyll $a$

22 data, we can explicitly examine the impact of local and transport processes on

23 phytoplankton biomass over a range of timescales from hourly to annually. For the

24 Upper James River, results show that the relative importance of local and transport

25 processes differs on different timescales. Local processes dominate phytoplankton

26 variability on daily to weekly timescales, whereas the contribution of transport

27 processes increases on seasonal to annual timescales and reaches equilibrium with local

28 processes. With the use of the transport rate and high-frequency chlorophyll $a$ data, a
\end{abstract}


29 method similar to the open water oxygen method for metabolism is also presented to

30 estimate phytoplankton primary production.

31 Keywords: Transport rate; phytoplankton biomass; high-frequency observational data;

32 primary production; timescale; open water method 


\section{Introduction}

Phytoplankton dynamics, such as the variability of biomass at a location, are controlled by both local processes and physical transport processes. Local environmental conditions, such as temperature, light, nutrient supply, and grazing pressure, strongly regulate phytoplankton growth and primary production through both

37 bottom-up and top-down controls (Kremer and Nixon, 1978). Transport processes in

38 aquatic systems, including advective transport and diffusive transport, affect

39 phytoplankton biomass by redistributing either biomass (direct effect), or dissolved and

40 particulate constituents such as nutrients that regulate phytoplankton growth (Lucas et

41 al., 1999; Cloern, 2001; Paerl et al., 2006; Lancelot and Muylaert, 2011).

42 The interactions between local and transport processes are complex, and their

43 contributions to phytoplankton dynamics can vary under different dynamic conditions.

44 Because each external forcing (e.g. tide, flow, and wind) and environmental factor (light

45 and temperature) has its own periodic fluctuation, the fluctuation will affect these two

46 processes. We hypothesize that the relative importance of local and transport processes

47 varies with timescales, which is also indicated by previous literature. Lucas et al. (2006)

48 suggest that intra-daily variability of phytoplankton biomass is largely controlled by both

49 the diurnal light cycle and the semidiurnal tidal oscillation, which implies the importance

50 of contributions from both local environmental conditions and tide on the hourly

51 timescale. Lake et al (2013) conduct measurements of photosynthetic rates and

52 integrate daily production on summer months in the York River for both the spring and

53 neap tides. They find that daily primary production does not show a clear variation 
54 during spring-neap cycle, which suggests that the local biological processes are

55 dominant for daily primary production rather than transport processes. Shen et al.

56 (2008) show that the high biomasses of macroalgae and phytoplankton are the

57 dominant cause of diurnal variation of dissolved oxygen concentration (DO) resulting

58 from high production during daytime and high respiration at night. It suggests that local

59 biological processes can be the dominant processes for primary production for the daily

60 timescale in estuaries and shallow-water systems. Conversely, changes in freshwater

61 discharge are considered to be a major factor driving strong seasonal and annual

62 patterns of phytoplankton biomass in river-dominated estuaries, which modulate the

63 location and strength of algal blooms through transport and nutrient supply (Valdes-

64 Weaver et al., 2006; Reaugh et al., 2007; Costa et al., 2009; Peierls et al., 2012).

65 Bukaveckas et al. (2011) show that algal blooms vary longitudinally along the Upper

66 James River, and peak at the location where residence time becomes large due to a

67 change of geometry, where about two-thirds of the net primary production is respired

68 locally, and the remaining one-third is transported out of the region by fluvial and tidal

69 advection. It suggests that the variability of phytoplankton biomass can be altered by a

70 dynamic condition resulting from a change of local geometry.

71 These studies point out the relative importance of transport processes compared to

72 local biological processes on particular timescales. However, due to the difficulty to

73 explicitly separate their contributions, few contributions to the literature discuss how

74 the comparison changes over a range of timescales from days to years though which is

75 interesting to know for some studies. For example, Lucas et al. (2009) suggest that the 
76 variability of phytoplankton biomass can be described by a steady-state balance

77 between local biological processes and transport processes described by residence time

78 (i.e., it assumes that the variability of phytoplankton biomass is negligible, and local and

79 transport processes are equal but counterbalanced in contribution). While this steady-

80 state balance assumption may hold for long-term timescales, it is questionable for

81 short-term timescales, such as daily and weekly timescales. A relevant discussion on the

82 comparison of relative importance of the two processes is helpful to answer on what

83 range of timescales the assumption is valid.

84 The relative importance of each process on phytoplankton dynamics also needs to

85 be evaluated for studies based on in situ observational data. As the development of

86 instruments, many water quality parameters like DO and chlorophyll-a fluorescence can

87 be measured in situ at 15-minute intervals, which is often referred to as high-frequency

88 data (http://web2.vims.edu/vecos/). The easy accessibility of high-frequency DO data

89 has prompted wide applications of the open water method for estimating ecosystem

90 primary production and metabolism (Odum, 1956; Howarth and Michaels, 2000; Cole et

91 al., 2000; Caffrey, 2004; Kemp and Testa, 2011). When applying this method for

92 estimating daily ecosystem primary production and metabolism, the effect of physical

93 transport processes is usually neglected (Staehr et al., 2010). This estimation without

94 considering transport, however, may have large biases when biological metabolism or

95 DO is significantly influenced by transport processes (Kemp and Boynton, 1980). In the

96 discussion section of this study, we applied a similar open water method to estimate

97 phytoplankton primary production using high-frequency chl-a concentration (denoted 
98 by $c h l-a$ ) data. The question as to whether the approach will cause more bias using

99 phytoplankton data is unknown as spatial horizontal gradients of $c h l-a$ are often larger

100 than those of DO. To evaluate the approach, the contribution of the transport processes

101 on the daily timescale needs to be addressed.

102 The objective of this study is to evaluate how the relative importance of local and 103 transport processes to the local variability of phytoplankton biomass vary over a range

104 of timescales from hours to years. Because the transport processes not only affect the

105 phytoplankton biomass but also affect the nutrient transport, when evaluating the

106 relative importance of transport processes to biomass variability, the contribution of

107 transport processes is restricted to the direct effect that redistributes biomass, and

108 therefore other indirect effects that regulate phytoplankton growth, such as

109 temperature, light availability, and nutrient limitation, are attributed to the contribution

110 of local processes. The Upper James River was selected as the study site where both

111 local and transport processes contribute greatly to phytoplankton dynamics

112 (Bukaveckas et al., 2011).

\section{Methods}

113 In this section we first presented how to attribute the variability of phytoplankton

114 biomass to the contributions of local and transport processes separately by

115 decomposing the transport equation. Then we presented a detailed procedure to

116 compute each contribution by using in situ observational phytoplankton data and

117 dynamic fields. The phytoplankton biomass dynamics and contribution of local 
118 processes were estimated using observational data, while the contribution of transport

119 processes was estiamted using dynamic fields computed by a dynamic model. Lastly, we

120 statistically analyzed to evaluate the relative importance of local and transport

121 processes, repectively, over a range of timescales.

\section{2.1. Decompose change of biomass}

123 The observation of phytoplankton data can be described by a three-dimensional

124 transport equation with source and sink terms (Chapra, 1997). For simplicity, the first-

125 order reaction transport equation for volumetric phytoplankton biomass in the $x$ -

126 direction can be expressed as follows:

$$
\frac{\partial C}{\partial t}+u \frac{\partial C}{\partial x}-\frac{\partial}{\partial x}\left(K \frac{\partial C}{\partial x}\right)=g C
$$

128 where $C$ denotes volumetric phytoplankton biomass $\left(\mathrm{g} \mathrm{C} \mathrm{m}^{-3}\right), x$ and $t$ denote location

129 and time, respectively, $u$ is current velocity $\left(\mathrm{m} \mathrm{s}^{-1}\right), K$ is diffusivity $\left(\mathrm{m}^{2} \mathrm{~s}^{-1}\right)$, and $g$ denotes

130 the growth rate of phytoplankton $\left(\mathrm{d}^{-1}\right)$ as a result of local processes. We combined

131 growth and loss as a net growth term $g$, as $g=G-R-M$, where $G$ is the gross

132 growth rate, $R$ is the respiration/excretion rate, and $M$ is the mortality rate due to both

133 grazing and settling. The gross growth rate $G$ is a function of available light, nutrients,

134 and temperature (Chapra, 1997). Note that Eq. (1) only includes terms in the $x$-direction

135 for making the following derivations clear and all variables vary vertically. The terms on

136 the left-hand side of Eq. (1) are the time derivative term, advective transport, and

137 diffusive transport, respectively. Transport processes may increase local concentration

138 of a property if the incoming water has higher concentrations, or decrease it if the 
139 incoming water has lower concentrations. Thus, the impact of transport processes does

140 not only depend on hydrodynamic fields ( $u$ and $K$ ) but also on the horizontal gradient of

141 phytoplankton biomass $(\partial C / \partial x)$.

142 Areal phytoplankton biomass $\left(\mathrm{g} \mathrm{C}^{-2}\right)$ can be conventionally obtained by vertical

143 integration of volumetric phytoplankton biomass $C$ from the bottom to the surface, i.e.,

$144 B=\int_{0}^{H} C d z$, where $z$ is the vertical location, and $H$ is the water depth $(\mathrm{m}), B=C \cdot H$ if

145 the water column is well-mixed. As no phytoplankton is transported across the surface

146 or the bottom, integrating Eq. (1) gives the transport equation for areal phytoplankton

147 biomass:

$$
\frac{\partial B}{\partial t}+\int_{0}^{H}\left[u \frac{\partial C}{\partial x}-\frac{\partial}{\partial x}\left(K \frac{\partial C}{\partial x}\right)\right] d z=g_{B} B
$$

149 where $g_{B}$ is the vertical mean growth rate that accounts for the growth of areal biomass $150 B$.

151 Analogous to the algal growth for biological process, we express transport processes

152 as a transport rate $F_{B}$, which is defined as

$$
F_{B}=\frac{1}{B} \int_{0}^{H}\left[u \frac{\partial C}{\partial x}-\frac{\partial}{\partial x}\left(K \frac{\partial C}{\partial x}\right)\right] d z
$$

154 and the governing equation (1) can be transformed into the expression:

$$
\frac{\partial B}{\partial t}=\left(g_{B}-F_{B}\right) B
$$

156 Dividing Eq. (4) by $B$ on both sides gives the equation for the rates:

$$
\frac{1}{B} \frac{\partial B}{\partial t}=g_{B}+\left(-F_{B}\right)
$$


158 Note that the impact of transport processes, expressed by $F_{B}$ in Eq. (3), depends on

$159 \partial C / \partial x$. The non-zero $\partial C / \partial x$ can be caused by either the change of dynamic conditions

160 due to interaction between forcings (i.e., flow, tide) and geometry, or the spatially

161 inhomogeneous local biological processes. Thus, the contribution of transport processes

162 in fact comes from both the dynamically induced transport (referred to as physical

163 transport) and the non-physical transport. The contribution of non-physical transport

164 can be expected to be relatively small locally as biological processes have less spatial

165 gradient compared to the physical transport. Our interest is to understand the physical

166 transport that contributes the change of biomass. We introduce transport rate $F$ that

167 only expresses the physical transport and we can now write Eq. (5) as follows:

168

$$
\begin{aligned}
r & =\underbrace{g_{B}}_{\text {Local }}+\underbrace{(-F)}_{\text {Physical Transport }}+\underbrace{\left(F-F_{B}\right)}_{\text {Non-physical transport }} \\
& =\underbrace{\mu_{\text {Lcal }}^{*}}_{\text {Physical Transport }}+\underbrace{(-F)}_{\text {Ph) }}
\end{aligned}
$$

169 where $r$ is the rate to express the variability of phytoplankton biomass as $r=\frac{1}{B} \frac{\partial B}{\partial t}=$

$170 \frac{\partial \ln B}{\partial t}$, and can be estimated from in situ observations of phytoplankton biomass $B$. The

171 physical transport rate $F$ is unknown but it can be estimated by using hydrodynamic

172 field and boundary conditions. $\mu=g_{B}+\left(F-F_{B}\right)$, which represents the growth rate of

173 biomass that resulted from the combined local contributions. Once we know both

174 values of $r$ and $F, \mu$ can be computed as $(r-F)$. When $g_{B}$ is zero (such as conservative

175 properties) or it is spatially homogenous, $F$ equals $F_{B}$, and $\mu$ equals $g_{B}$. We will refer to

$176 r$ as the relative growth rate, and to $\mu$ as the effective growth rate in the following

177 sections. As $F$ only represents the transport contribution, a negative $F$ value corresponds 
178 to a "transport in" process that increases biomass, and a positive $F$ value corresponds to

179 a "transport out" process that decreases biomass in accordance with Eq. (6), and a zero

$180 F$ means there is no contribution of transport processes on local phytoplankton

181 variability.

182 Eq. (6) demonstrates that the relative change of biomass is a result of competition

183 between local and transport processes, and their contributions could be evaluated by

184 comparing the effective growth rate $\mu$ to the transport rate $F$ :

$185 \quad$ 1) $\mu>F$ leads to $r>0$, biomass increases

186 2) $\mu<F$ leads to $r<0$, biomass decreases

187 3) $\mu=F$ leads to $r=0$, biomass remains constant

188 Note that $\mu$ and $F$ could both have negative values. For example, the observed biomass

$189 B$ at a location may increase at night $(r>0)$ when photosynthesis does not occur $(\mu<0)$,

190 but biomass can increase due to a transport of biomass to this location $(F<0$,

191 "transport in").

$192 \quad$ 2.2. Study site

193 The James River is a tributary of the lower Chesapeake Bay located along the U.S. East

194 Coast (Fig. 1). The Upper James River is the tidal freshwater region where salinity is

195 between 0 and 0.05 . Calibrated time series data (15-minute intervals) were collected

196 from Chesapeake Bay Continuous Monitoring Station JMS073.37 at the Virginia

197 Commonwealth University Rice Rivers Center ('RC', green triangle,

198 http://web2.vims.edu/vecos/), from March to November 2006, 2007, and 2008. Data 
were measured using YSI 6600 data sondes with the Clean Sweep Extended Deployment

200 System, include a number of parameters such as chl-a, temperature, turbidity, and

201 water depth $(H)$. All calibration and maintenances follow the YSI, Inc. operating manual

202 methods. Particularly, chl-a data were obtained using laboratory calibrated sensors that

203 converts in vivo fluorescence of chlorophyll $a$ to $c h l-a$. The sondes were deployed

204 around 0.5 to 0.9 meters below the surface of the water during the observational

205 period, while the mean water depth $H$ was about $2.5 \mathrm{~m}$, and the mean tidal range was

206 about $0.76 \mathrm{~m}$ at Station RC. Hourly irradiation data were obtained at nearby Richmond

207 Airport. Also, monthly time series data of surface chl-a were collected from Chesapeake

208 Bay Program Long-term Monitoring Stations TF5.4 and TF5.5 (blue squares).

209 The monthly data were used for three long-term timescales (monthly, seasonal, and

210 annual), while the high-frequency data were used to analyze the relative importance of

211 each contribution for continuously increased timescales from hourly to annually.

212 2.3. Compute relative growth rate

213 As the instantaneous relative growth rate is defined as $r=\frac{\partial \ln B}{\partial t}$, the solution

214 is $B_{t+d t}=B_{t} e^{r \cdot d t}(d t \rightarrow 0)$, which computes biomass measured at time $t+d t\left(B_{t+d t}\right)$

215 from the biomass at time $t\left(B_{t}\right)$. This indicates that the relative growth rate can be

216 calculated by the change of biomass. Thus, for a time series of in situ measured

217 phytoplankton biomass with an observational time interval of $\Delta t$, a time series of

218 relative growth rate $r_{\Delta t}$ that reflects the change in biomass from time $t$ to $t+\Delta t$ can be

219 calculated as: 


$$
r_{\Delta t}=\frac{1}{\Delta t}\left[\ln \left(B_{t+\Delta t}\right)-\ln \left(B_{t}\right)\right]=\frac{1}{\Delta t} \ln \left(\frac{B_{t+\Delta t}}{B_{t}}\right)
$$

221 where $B_{t}$ and $B_{t+\Delta t}$ are the biomass measured at times $t$ and $t+\Delta t$, respectively. For

222 example, $r_{\Delta t}$ is the relative growth rate over daily timescale when $\Delta t=1 \mathrm{~d} ; r_{\Delta t}$ is the

223 relative growth rate over monthly timescale when $\Delta t=30 \mathrm{~d}$.

224 chl- $a$ data were used to obtain phytoplankton biomass. High-frequency chl-a data

225 collected at 15-minute intervals were first smoothed to 1-h averages. Using hourly mean

$226 \mathrm{chl}-a$ in the units of $\mathrm{g} \mathrm{m}^{-3}$, the biomass in the water column can be estimated as $B=C$.

$227 H=(C: c h l-a) \cdot \operatorname{chl}-a \cdot H$. Here, the assumption of a well-mixed water column was

228 applied. This assumption is reasonable for the shallow Upper James River with no

229 persistent stratification (Bukaveckas et al., 2011), while the mean euphotic depth is

230 about 2-3 $\mathrm{m}$. For a constant C: $c h l-a$ ratio $(\mathrm{g} \mathrm{C/g} \mathrm{chl-a),} \mathrm{the} \mathrm{rate} \mathrm{can} \mathrm{be} \mathrm{estimated}$

231 according to Eq. (7):

$$
r_{h r}=\frac{1}{\Delta t} \ln \left[\frac{(c h l-a \cdot H)_{t+\Delta t}}{(c h l-a \cdot H)_{t}}\right], \text { with } \Delta t=1 h r
$$

233 where the subscript " $h r$ " denotes the observed hourly growth rate, and C: chl-a ratio

234 was withdrawn since it did not affect rate computation. The $C$ : $c h l-a$ ratio varies with

235 seasons and species, which can be measured using observations. We applied a constant

236 C: chl-a ratio at Stations TF5.5 and RC as the seasonal variation of C:chl-a ratio is

237 relatively small and the average $C$ : chl-a ratio was $39 \pm 2 \mathrm{~g} \mathrm{C/g} \mathrm{chl-a} \mathrm{(Bukaveckas} \mathrm{et} \mathrm{al.,}$ 238 2011). 


\subsection{Compute transport rate}

240 The transport rate $F$ can be computed based on a conservative tracer using a 3D

241 numerical model. For a conservative $\operatorname{tracer} \theta$, it is governed by Eq. (1) with zero growth

242 rate (Note that $C$ is replaced by tracer concentration $\theta$ for clarity):

243

$$
\frac{\partial \theta}{\partial t}+\frac{\partial u \theta}{\partial x}+\frac{\partial v \theta}{\partial y}+\frac{\partial w \theta}{\partial z}=\frac{\partial}{\partial x}\left(K_{x} \frac{\partial \theta}{\partial x}\right)+\frac{\partial}{\partial y}\left(K_{y} \frac{\partial \theta}{\partial y}\right)+\frac{\partial}{\partial z}\left(K_{z} \frac{\partial \theta}{\partial z}\right)
$$

244 where $u, v, w$ represent velocities in the $x, y$, and $z$ directions, respectively; and $K_{x}, K_{y}, K_{z}$

245 represent diffusivities in the $x, y$, and $z$ directions, respectively. For the modeling

246 domain, no tracer comes from the boundaries at all times, i.e. $\theta_{\text {in }}=0$ at both river and

247 open boundaries. By using this boundary condition, it assumes that phytoplankton in

248 the Upper James River are mainly from autochthonous sources, which is reasonable in

249 James River as the $c h l-a$ at the fall-line of the James River is much lower than the $c h l-a$

250 downstream (Bukaveckas et al., 2011). The initial condition, $\theta_{0}=1$, is set everywhere

251 within the domain. The tracer is transported by the dynamic fields, which results in the

252 change of horizontal tracer gradient due to the change of geometry and dynamic forcing

253 conditions. Therefore, the transport rate for tracer concentration, $F_{\theta}$, can be computed

254 as $F_{\theta}=-\frac{\partial \theta}{\theta \partial t}=-\frac{\partial \ln \theta}{\partial t}$, and the transport rate $F$ used in this paper to represent the

255 contribution of transport processes can be computed as $F=-\frac{1}{\int_{0}^{H} \theta d z} \frac{\partial \int_{0}^{H} \theta d z}{\partial t}$. Because

256 the rate of $F$ is normalized by the tracer, the initial condition and the magnitude of the

257 tracer concentration will not affect the model results after a sufficient initial simulation

258 period, and the impact of the initial condition is negligible in the calculation of $F$. 
A real-time three-dimensional numerical model for the James River was developed

260 (Shen et al., 2016) using the Environmental Fluid Dynamics Code (EFDC), and it has a

261 good spatial resolution to represent the local variation of complex geometry. The model

262 was forced by hourly tide and salinity at the mouth and hourly wind and heat flux

263 obtained at nearby airport stations, which account for both tidal and meteorological

264 variation. The model was calibrated and verified from 1990-2013 for both

265 hydrodynamics and water quality (Shen et al., 2016). There are a total of 3,066 grid cells

266 in the horizontal and eight layers in the vertical. The model was also used to compute

267 water age in the James River (Shen and Lin, 2006). As the cross-section of the Upper

268 James is narrow and located in the freshwater region without salinity-induced

269 stratification, the volume-controlled freshwater residence time was estimated as the

270 difference of the lateral mean water age at the control section near Stations TF5.4 and

271 TF5.5 along the main channel.

272 With the use of the numerical model, the transport rate $F$ over the entire time series

273 from 2006 to 2008 was computed based on Eq. (9) with specific boundary and initial

274 conditions described above.

275 2.5. Compute rates for each timescale

276 Mean rates for timescales longer than the hourly timescale can be obtained by taking

277 the average of the hourly rate $r_{h r}$ over the given time interval of $\Delta t$ through the

278 following equation:

279

$$
\bar{r}=\frac{1}{\Delta t} \int_{t}^{t+\Delta t} r_{h r} d t=\frac{1}{\Delta t} \int_{t}^{t+\Delta t} \frac{\partial \ln B}{\partial t} d t=\frac{1}{\Delta t}\left[\ln \left(B_{t+\Delta t}\right)-\ln \left(B_{t}\right)\right]
$$


280 It can be seen that the mean rate only depends on the biomass at the beginning and

281 ending time for the interval of $\Delta t$. Therefore, rates for timescales longer than the hourly

282 timescale can be obtained by two equivalent methods, either using Eq. (7) with $\Delta t$

283 equals the particular timescale, or using the average as Eq. (10). Here, the two methods

284 Eq. (7) and Eq. (10) were applied to data at Station TF5.5 and RC, respectively. After we

285 obtain both $\bar{r}$ and $\bar{F}$, the effective growth rate $\bar{\mu}$ on that timescale was calculated using

286 Eq. (6), $\bar{\mu}=\bar{r}+\bar{F}$. The overbar will be dropped hereafter when we present results with

287 the understanding that the values are mean values.

\subsection{Evaluate contributions of local and transport processes}

289 Eq. (6) provides a way to evaluate the contributions of local processes and transport

290 processes to phytoplankton variability in terms of effective growth rate $\mu$ and transport

291 rate $F$. A statistical method is applied to evaluate the contributions of local and

292 transport processes. Correlation coefficient values, $\mathrm{R}^{2}$, between $F$ and $r$ and between $\mu$

293 and $r$, are calculated for each timescale to examine the proportions of the variance of $r$

294 that could be explained by $F$ and $\mu$, respectively. Additionally, the overall relative

295 importance of local and transport processes on each timescale can be quantified by

296 comparing the root-mean-square $(r m s)$ of the entire time series of $F$ and $\mu$ on that

297 timescale:

$$
\text { Local: } \frac{r m s(\mu)}{r m s(F)+r m s(\mu)} ; \text { Transport: } \frac{r m s(F)}{r m s(F)+r m s(\mu)}
$$

299 Note that, on each timescale, the relative importance of each process computed by

300 Eq. (11) used the entire time series of data during the observational period (1990-2013 
301 for Station TF5.5 and 2006-2008 for Station RC); and the analysis reflects their overall

302 contribution during the entire observational period on this timescale, indicating the

303 averaged relative importance or the contribution under normal conditions. The result of

304 short timescale does not represent their contribution over a shorter period during

305 abnormal conditions. For example, episodic events, such as storm surges and large

306 discharge events, may dramatically increase contribution of transport processes in a few

307 days at Station RC, and have greater impact on phytoplankton dynamics than local

308 processes during those events; but these signals were filtered out when considering the

309 entire observational period, and it will later be shown that the change of phytoplankton

310 biomass on daily timescales was overall dominated by local processes (Section 3.7).

\section{Results}

\subsection{Evaluation of contribution of transport processes}

312 By comparing the transport rate to the relative growth rate, the contribution of

313 transport process to phytoplankton biomass variability was evaluated over a sequence

314 of timescales. Note that for long-term timescales (monthly, seasonal, and annual), we

315 only presented results from long-term monitoring data at Station TF5.5, and

316 summarized results from high-frequency data at Station RC at Table 1, and the results

317 from two data sources are comparable.

\subsection{Short-term timescales}

319 The correlation of the relative growth rate $r$ and the transport rate $F$ for a 3-year

320 period was analyzed using the high-frequency data for timescales shorter than daily 
321 (Table 1). Overall, their correlations were quite low, suggesting that transport processes

322 were not the dominant processes to phytoplankton variability for those timescales

323 during the observation period.

324 The tide in this estuary shows a semidiurnal cycle. From a transport perspective, the

325 net effect of transport on biomass is more important in tidal and daily timescales.

326 However, for an intratidal scale, the tide can have a large influence on biomass during

327 the flood and ebb periods, which will modulate the phytoplankton concentration in the

328 water column. The contribution of tide, therefore, is expected to play an important role

329 in the phytoplankton dynamics during food and ebb periods. An example from October

3302008 is shown in Fig. 2. Rates $r$ and $F$ on the timescale of $6 \mathrm{~h}$ were significantly linearly

331 correlated $\left(R^{2}=0.52, p<0.001\right)$. The correlation was even higher when only nighttime

332 data were used (Fig. $2 c, R^{2}=0.54, p<0.001$ ). A strong tidal signal was observed that

333 indicated both rates were modulated by the semidiurnal tide.

334 The 6-h averaged time series data revealed that increases in phytoplankton biomass

335 occurred during the night $(r>0)$ when no photosynthesis occurred (Fig. 2c), and the

336 mass increase corresponded to a negative transport rate (note that figure plots use $-F$ ),

337 which suggests that the increases in biomass at night were caused by a "transport in"

338 process due to the transport induced by tides and freshwater discharge. Although the

339 tide can modulate the intratidel transport processes, the large intratidal variability will

340 be filtered for a tidal or daily period and the influence of net physical transport

341 processes on biomass on tidal and daily timescales is not as important as local processes

342 (Table 1). 


\subsection{Monthly timescale}

344 The time series of chl- $a$ and local residence time for the period of 2000-2013 at 345 Station TF5.5 is plotted in Fig. 3a. This figure shows that $c h l-a$ and residence time had 346 the same variations. On a monthly timescale, chl-a correlated with the residence time $347 \quad\left(R^{2}=0.33, p<0.001\right.$, Fig. 3b). Lower chl-a was shown to correspond with shorter 348 residence time, though the correlation was more diverse when residence time was long, 349 which usually occurred in the summer, indicating that the contribution of local 350 processes is more important during summer when the dynamic conditions become 351 favorable for growth.

352 The transport rate $F$ was correlated to the relative growth rate $r$ at Station TF5.5 for 353 the period from 2000 to $2013\left(R^{2}=0.25, p<0.001\right)$ as shown in Fig. 3c and 3d.

354 Variations of $r$ and $F$ were in phase, in general, which suggests that the monthly 355 variability of phytoplankton biomass is modulated by hydrodynamics. Note that only 13356 year result was presented in Fig. 3 for making the plot clear, and the correction between $357 \quad r$ and $F$ during the entire years of long-term monitoring data (1990-2013) was shown in 358 Table 1.

\subsection{Seasonal timescale}

360 For the seasonal timescale, analysis of the time-series data from the years 1990 to 3612013 showed that transport rate $F$ was correlated with relative growth rate $r\left(R^{2}=0.22\right.$, $362 p<0.001$, Fig. $4 b)$. The transport rate $F$ remained positive, and transport processes had 363 a net "transport out" effect on phytoplankton biomass throughout the observation 364 period (Fig. 4a). The relative growth rate $r$ had either positive or negative values, but the 
corresponding effective growth rate $\mu$ was always positive, suggesting that the contribution of local processes leads to an increase in phytoplankton biomass.

367 All three rates $(r, F$, and $\mu$ ) showed seasonal variations (Fig. 5). The transport rate, $F$, 368 appeared to have smaller magnitudes during summer than during other seasons, 369 corresponding to the lowest freshwater discharge into the James River in the summer.

370 The effective growth rate, $\mu$, seemed to be lower during summer and fall than during 371 spring and winter. This seasonal change can be attributed to a change in composition of

372 algal species and an increase in respiration, grazing, and nutrient limitation during the 373 summer (Marshall and Egerton, 2013). As a consequence, the relative growth rate 374 tended to be low during summer and fall, even though $F$ was lower. It shows that $\mu$ was 375 much larger than $r$, after removal of the impact of transport processes (Fig. 5), indicating 376 the values of $r$ would underestimate the effective growth rate of phytoplankton without 377 considering any effect of the physical transport.

\section{$378 \quad$ 3.5. Annual timescale}

379 For the annual timescale, the correlation between $F$ and $r$ was significant $\left(R^{2}=0.48, p\right.$ $380<0.001$, Fig. 4b) and it was higher than the correlation between $\mu$ and $r\left(R^{2}=0.24, p<\right.$ 381 0.001). Similar to the seasonal timescale, both $F$ and $\mu$ remained positive, while the 382 magnitude of the relative growth rate $r$ diminished (Fig. 4c), indicative of the balance 383 between local and transport processes. The contribution of transport processes showed 384 a net "transport out" effect on interannual phytoplankton biomass variability in the 385 Upper James River, i.e. more biomass was transported out of this region than was 386 transported in. 


\section{6. $\quad$ Rate variations}

388 The daily effective growth rate, $\mu$, may be of the same magnitude as the gross growth 389 rate, $G$, if respiration and grazing pressure are very low. Theoretically, the daily gross 390 growth rate represents photosynthetic production, and it has maximum values ranging 391 from 1 to $5 \mathrm{~d}^{-1}$ dependent on the temperature, nutrients, and phytoplankton species 392 (Eppley, 1972; Brush et al., 2002). However, the estimated effective growth rate may be 393 an order of magnitude smaller than the theoretical maximum values, due to suppression 394 of photosynthesis by nutrient and light limitation, respiration, settling, and grazing. The 395 variability of $\mu$ reflects a net response of phytoplankton to the change of local 396 environment conditions.

397 We used median rates as representative of typical values for each timescale (Fig. 6a).

398 Positive values of the rates $r, \mu$ and $-F$ corresponded to the increase of phytoplankton 399 biomass whereas negative values indicated a decrease. Both medians of positive and 400 negative rates, respectively, are listed in Table 1. In general, both the medians of 401 positive and negative rates decreased as the timescale increased.

402 For seasonal or longer timescales, the medians of transport rates $(-F)$ were negative 403 at Station RC (Table 1 ). In fact, - $F$ was always negative on these long-term timescales, 404 suggesting that the net contribution of transport processes flushed biomass 405 downstream ("transport out"). $\mu$ was always positive, suggesting that the net 406 contribution of local processes was to increase the phytoplankton biomass, i.e., 407 phytoplankton primary production was larger than the loss from respiration, excretion, 408 settling, and grazing. The competition between local and transport processes leads to 
409 either an increase or a decrease of phytoplankton biomass, which was reflected by the

410 existence of both positive and negative values of $r$ when the timescale exceeded the

411 monthly timescale.

\subsection{Relative importance of local and transport processes}

413 The increased correlation between rates $F$ and $r$ from a monthly timescale to an

414 annual timescale, based on analysis of long-term monthly monitoring data at Station

415 TF5.5, suggested that the relative importance of the transport processes to

416 phytoplankton variability increases when evaluating it on a longer timescale. This result

417 was consistent with the evaluation using high-frequency data at Station RC during 2006

418 to 2008 (Fig. $6 \mathrm{c}$ and $6 \mathrm{~d}$ ). The coefficient of determination, $\mathrm{R}^{2}$, also showed that the

419 proportions of $r$ variance that could be explained by the transport rate $F$ increased with

420 the increase of timescale, whereas the proportions that could be explained by the

421 effective growth rate, $\mu$, decreased.

422 The relative importance of contributions of local and transport processes over

423 continuously increasing timescales were compared for the period from 2006 to 2008

424 (Fig. 6d). The relative importance of transport processes had an increasing trend with

425 increasing timescale whereas that of local processes had a decreasing trend, and they

426 were equally important in the monthly timescale at Station RC. The relative importance

427 of each contribution was more diverse in timescales shorter than daily; it shows that the

428 contribution of local processes peaked on daily and tidal timescales, whereas the

429 transport processes showed peaked relative importance on timescales around 6 and 18

$430 \mathrm{~h}$ (Fig. $6 \mathrm{~d}$ ). These variations are caused by the intratidal variability and will be discussed 
431 in the next section. It can be seen that tide also modulates the local processes though

432 the net tidal contribution is less.

\section{Discussion}

\subsection{Factors affecting local and transport processes}

434 Similar to the hydrodynamic conditions investigated for many other estuaries (Wang

435 et al., 2004; Barcena et al., 2012; Lemagie and Lerczak, 2015), river inflow and tides are

436 the two primary factors affecting the transport processes in the Upper James River and

437 contribute to phytoplankton biomass dynamics, while other forcings such as wind play

438 less important roles.

439 River inflow determines the overall net long-term advection characteristics of the

440 Upper James River. The phytoplankton biomass transported from the upstream

441 freshwater is generally found to be smaller than the biomass generated in the tidal

442 freshwater region and estuary (e.g., Bukaveckas et al., 2011; Peierls et al., 2012; Paerl et

443 al., 2014). As the residual current always flows downstream, the biomass is transported

444 downstream, resulting in a net "transport out" effect on phytoplankton biomass when

445 viewing it from a long-term perspective. Consistently, river inflow also had the net

446 "transport out" effect in the Upper James River, reflected by only positive medians of

447 transport rate $F$ found on the annual timescale (Table 1 ).

448 Tides also have substantial effects on phytoplankton variability. The dominant

449 constituent of tide in the Upper James River is the semi-diurnal $\mathrm{M}_{2}$ tide with a 12.42-h

450 tidal period. Both advective and diffusive transport are enhanced during either flood or 
451 ebb tides, which increase the relative importance of transport processes on a timescale

452 of about one-half of the tidal period (around $6 \mathrm{~h}$ ); whereas the largest relative

453 importance of local processes is around tidal and daily timescales, because the net

454 impact on transport processes from tides is minimal by averaging over a complete tidal

455 cycle, it is consistent with results in Fig. 6c and d.

456 The local processes are fundamental for phytoplankton variability, regardless of the

457 transport processes. It is found that local processes always have an important

458 contribution to the phytoplankton biomass dynamics in the Upper James River even on

459 the timescales with a large physical contribution (Fig. 6d). For the monthly timescale,

460 the results are more scattered with an increase of residence time (Fig. 3b), these large

461 residence times usually occurred in summers when both riverine flows and transport

462 rate were small (Fig. 5), and the contribution of local processes became relatively more

463 important than that of transport processes. Local processes play critical roles on diurnal

464 timescales, owing to the well-recognized diurnal variation that phytoplankton biomass

465 increases during the day because of photosynthesis, but decreases at night.

466 The contribution of local processes also showed seasonal variations represented by

467 the effective growth rate $\mu$ (Fig. 5). In general, a smaller value of $\mu$ appeared in summer

468 and fall than during winter and spring. One possible reason for this seasonal change is

469 the phytoplankton species succession. The "transport out" effect by freshwater has

470 been found to be a determining factor on phytoplankton growth and composition in

471 river-dominated estuaries as it tends to select fast-growing species in high-flow

472 conditions (Ferreira et al., 2005; Paerl et al., 2006; Costa et al., 2009). The maximum 
473 freshwater discharge occurs in the winter and spring in the James River. The enhanced

474 "transport out" processes along with abundant nutrients favors freshwater diatoms that

475 have relatively high intrinsic growth rates to become the dominant species in these two

476 seasons. In the summer and fall, when the "transport out" effect is reduced and

477 residence time increases, the percentage contribution of dinoflagellates and

478 cyanobacteria with lower intrinsic growth rates increases (Valdes-Weaver et al., 2006;

479 Marshall and Egerton, 2013). Temperature, nutrients, and grazing may be other factors

480 affecting the seasonal change of the contribution of local biological processes, as

481 respiration and grazing often peak in summer while nutrient limitation is severe though

482 with large benthic flux input of recycled nutrients (Kemp et al., 2005).

$483 \quad$ 4.2. Long-term validation

$484 \quad$ Complex phytoplankton dynamics can be described by the balance between local and 485 transport processes under steady-state conditions (Lucas et al., 2009), and it is expected 486 that this balance is acceptable on long-term timescales but may be questionable on 487 shorter timescales. Therefore, it is interesting to examine on which timescales this 488 assumption is valid.

489 The steady-state assumption is equivalent to assuming that $r=0$, or that the 490 magnitude of $r$ is negligible compared to the magnitudes of $\mu$ and $F$. Direct comparisons 491 of $r$ to $\mu$ and $F$ show that the assumption is valid for seasonal to annual timescales in 492 the region as $r$ is small. By using the root-mean-square $(r m s)$ of each rate to quantify 493 their magnitudes, it is found that the ratios of $r m s(F)$ to $r m s(r)$ and $r m s(\mu)$ to $r m s(r)$ 494 increased as timescales increased (Fig. 6b). This suggests that contributions of local and 
495 transport processes have the tendency to be balanced only when the timescale is longer

496 than 10 days (Fig. 6a and b). Their difference becomes more significant for hourly to

497 daily timescales.

\section{$498 \quad$ 4.3. Phytoplankton primary production}

499 The open water method using high-frequency dissolved oxygen data has been widely 500 applied to estimate gross primary production, ecosystem respiration, and net ecosystem

501 metabolism (Staehr et al., 2012). Because of the influence of advection processes, high-

502 frequency phytoplankton data have not often been used to estimate these metabolic

503 rates. Here, we used high-frequency $c h l-a$ data to estimate phytoplankton gross primary

504 productivity similar to open water oxygen method and to evaluate the influence of

505 physical transport on estimation of the rate.

506 For each time interval (e.g. $\Delta t=15$ minutes), the change of phytoplankton biomass

$507(\Delta B)$ is described by the equation below:

508

$$
\frac{\Delta B}{\Delta t}=G P P-R P P-F P P
$$

509 where GPP is the 15-minute phytoplankton gross primary productivity $\left(\mathrm{g} \mathrm{C} \mathrm{m}^{-2} 15 \mathrm{~min}^{-1}\right)$, $510 R P P$ is the 15-minute rate of total phytoplankton respiration and consumption (including 511 respiration, grazing, and settling, $\left.\mathrm{g} \mathrm{C} \mathrm{m}^{-2} 15 \mathrm{~min}^{-1}\right)$, which represents total biological 512 losses. FPP is the 15-minute rate of transport in or out of phytoplankton by transport 513 processes $\left(\mathrm{g} \mathrm{C} \mathrm{m}^{-2} 15 \mathrm{~min}^{-1}\right)$; a positive $F P P(-F<0)$ means that the carbon produced by 514 local biological processes is transported out of this location and benefits the food web in 
515 adjacent areas (Cloern, 2007). We also use DPP to denote the difference between GPP 516 and $R P P$,

$$
D P P=G P P-R P P
$$

518 FPP is estimated from the product of phytoplankton biomass and transport rate, and 519 it was calculated using the transport rate $F$ computed from the numerical model in this 520 study $(F P P=F \cdot B)$. The method for computing GPP and $R P P$ is similar to the open 521 water method, and DPP was first computed by summation of $\Delta B / \Delta t$ and $F P P$ for each 522 time interval. Daily $R P P$ was estimated from the extrapolation of nighttime $R P P(=$ the 523 sum of nighttime 15-minute DPP) to one day; and daily GPP was estimated, according to 524 Eq. (13), from daily DPP (= the sum of 15-minute DPP over one day) plus daily RPP. Both 525 daily GPP and RPP are in units of $\mathrm{g} \mathrm{C} \mathrm{m}^{-2} \mathrm{~d}^{-1}$. Unrealistic negative values of daily GPP 526 were found for some days (about 24\%), and they were excluded from the calculations 527 following the way of the open water method (Caffrey, 2003). Most of the negative daily 528 GPP values appeared on rainy days when precipitation may enhance the flushing effect

529 from runoff from adjacent watersheds. The results are representative of primary 530 productivity and metabolic rates under normal weather conditions. Note that the 531 transport rate $F$ used was computed from the numerical model that only represents the 532 physical transport as shown in Eq. (6), and the results are only used to quantify the 533 influence of physical transport on the estimation of GPP.

534 For the Upper James River, the typical C: chl-a ratio equals $39 \mathrm{~g}$ C/g chl- $a$ with small 535 seasonal variability (Bukaveckas et al., 2011). Because we have no winter data, the 
536 annual phytoplankton primary production cannot be correctly estimated. Nevertheless,

537 we assumed that gross primary production in winter was lower than or equal to the

538 minimum of seasonal production. The annual phytoplankton gross primary production

539 were estimated to be about $255.90,685.91$, and $486.26 \mathrm{~g} \mathrm{C} \mathrm{m}^{-2} \mathrm{yr}^{-1}$, respectively, for the

540 years 2006, 2007, and 2008 (Table 2). These estimations were comparable to the $12-$

541 year averaged (1989-2001) annual phytoplankton gross primary production, around 230

$542 \mathrm{~g} \mathrm{C} \mathrm{m}^{-2} \mathrm{yr}^{-1}$, measured in the laboratory using ${ }^{14} \mathrm{C}$ method at Station TF5.5 (Nesius et al.,

543 2007). An example of the seasonal averages of GPP, RPP, and DPP in 2008 are also

544 shown (Fig. 7), and the seasonal average of GPP during the summer 2008 was $2.31 \mathrm{~g} \mathrm{C}$

$545 \mathrm{~m}^{-2} \mathrm{~d}^{-1}$, close to the seasonal mean rate of $2.11 \mathrm{~g} \mathrm{C} \mathrm{m}^{-2} \mathrm{~d}^{-1}$ using the method of dissolved

546 oxygen incubations for the nearby York River during the same time period (Lake et al.,

547 2013).

548 The amount of primary production transported out ranges from $7 \%$ to $13 \%$

$549(F P P / G P P)$. It suggests that the net physical transport processes have a minor impact on

550 estimates of GPP and RPP on daily scale under normal weather conditions. This is

551 consistent with the analysis of biomass variability on the daily timescale.

\section{Conclusions}

552 To evaluate the contribution of transport processes to phytoplankton biomass

553 variability using high-frequency observational data, we introduced the transport rate

554 method, which enables us to estimate each contribution exclusively as a first-order

555 approximation. The Upper James River was selected as the study site, and the results 
556 support the hypothesis that both local and transport processes contributed significantly

557 to the local variability of phytoplankton biomass, but their relative importance changed

558 on different timescales. On a short-term basis such as daily and weekly timescales, even

559 though the transport processes could modulate phytoplankton biomass variability on an

560 intratidal timescale due to flood and ebb variations, the intratidal variations will be

561 removed over a tidal cycle. The local processes dominated the overall contributions

562 during the observational period; however, the relative importance of transport

563 processes tended to be equivalent to the local processes in the long-term timescales

564 (e.g., seasonal and annual). Another analysis of this study shows that the local processes

565 were almost balanced by the transport process on the seasonal and annual timescales,

566 and approached a steady-state condition for phytoplankton dynamics, whereas the time

567 derivative term became important for shorter timescales.

568 Examination of the transport rate revealed that transport processes exhibited a

569 persistent "transport out" effect on long-term timescales to decrease in situ

570 phytoplankton biomass in this region, but it was not the case for timescales shorter than

571 seasonal that transport processes could either increase or decrease the biomass,

572 corresponding to "transport in" and "transport out" processes, respectively.

573 Transport processes had a small impact on the estimation of daily gross

574 phytoplankton productivity. By applying a method analogous to the open water oxygen

575 method that calculates phytoplankton gross primary production using 15-minute

576 observational data, the percentage of production flushed out was around $7-13 \%$ under

577 normal weather conditions. 
578 The use of the transport rate is a first-order approximation for quantifying transport

579 processes. Zero concentrations were applied at the boundaries for this study, and the 580 computed transport rate $F$ did not account for the possible effects of inputs from

581 boundaries (though these are very low), and therefore the contribution of the transport

582 processes considered was the redistribution of biomass produced within the study area

583 due to the change of dynamics and geometry. The additional bias of the transport rate

584 on the hourly timescale could come from the numerical method and model grid

585 resolution that may not be able to simulate the microscale varibility of physical

586 processes, which causes the patchiness of phytoplankton distribution that makes the

587 observed chl- $a$ data fluctuate highly with a change of dynamic conditions. Besides the

588 use of the numerical calculation, the transport rate can also be estimated based on field

589 observations of current, salinity and water depth. In addition, the pattern of the relative

590 importance of local and transport processes on different timescales demonstrated in

591 the Upper James River may vary at other locations of the estuary, which would warrant

592 further study.

\section{Acknowledgments}

593 The funding of this study was supported by the Virginia Institute of Marine Science 594 and the Virginia Department of Environmental Quality. We are thankful to Mark J. Brush 595 for his critical review of the manuscript and invaluable suggestions. We also thank Marjy

596 A.M. Friedrichs, and Kyeong Park for their comments and suggestions. We are grateful 597 to Mac Sisson for help editing the manuscript. We thank two anonymous reviewers for 598 their constructive comments that helped us to improve the manuscript. This is 
599 Contribution No. 3645 of the Virginia Institute of Marine Science, College of William and 600 Mary.

\section{References}

601 Bárcena, J.F., García, A., Gómez, A.G., Álvarez, C., Juanes, J.A. and Revilla, J.A., 2012.

602 Spatial and temporal flushing time approach in estuaries influenced by river and tide. An

603 application in Suances Estuary (Northern Spain). Estuarine, Coastal and Shelf

604 Science, 112, 40-51.

605 Brush, M.J., Brawley, J.W., Nixon, S.W. and Kremer, J.N., 2002. Modeling phytoplankton

606 production: problems with the Eppley curve and an empirical alternative. Marine

607 Ecology. Progress Series, 238, 31-45.

608 Bukaveckas, P.A., Barry, L.E., Beckwith, M.J., David, V. and Lederer, B., 2011. Factors

609 determining the location of the chlorophyll maximum and the fate of algal production

610 within the tidal freshwater James River. Estuaries and Coasts, 34(3), 569-582.

611 Caffrey, J.M., 2003. Production, respiration and net ecosystem metabolism in US

612 estuaries. Environmental Monitoring and Assessment, 81, 207-219.

613 Caffrey, J.M., 2004. Factors controlling net ecosystem metabolism in US

614 estuaries. Estuaries, 27(1), 90-101.

615 Chapra, S.C., 1997. Surface Water-Quality Modeling. McGraw Hill, New York, NY.

616 Cloern, J.E., 2001. Our evolving conceptual model of the coastal eutrophication

617 problem. Marine Ecology Progress Series, 210, 223-253. 
618 Cloern, J.E., 2007. Habitat connectivity and ecosystem productivity: Implications from a

619 simple model. The American Naturalist, 169(1), E21-E33.

620 Cole, J.J., Pace, M.L., Carpenter, S.R., and Kitchell, J.F., 2000. Persistence of net

621 heterotrophy in lakes during nutrient addition and food web manipulations Limnology

622 and Oceanography, 45, 1718-1730.

623 Costa, L.S., Huszar, V.L.M. and Ovalle, A.R., 2009. Phytoplankton functional groups in a

624 tropical estuary: hydrological control and nutrient limitation. Estuaries and

625 Coasts, 32(3), 508-521.

626 Eppley, R.W., 1972. Temperature and phytoplankton growth in the sea. Fisheries

627 Bulletin, 70(4), 1063-1085.

628 Ferreira, J.G., Wolff, W.J., Simas, T.C. and Bricker, S.B., 2005. Does biodiversity of

629 estuarine phytoplankton depend on hydrology?. Ecological Modelling, 187(4), 513-523.

630 Howarth, R., and Michaels, A.F., 2000. The measurement of primary production in

631 aquatic ecosystems, p. 72-85. In O. Sala, R. Jackson, H. Mooney, and R. W. Howarth

632 [eds.], Methods in ecosystem science. Springer-Verlag.

633 Kemp, W.M. and Boynton, W.R., 1980. Influence of biological and physical processes on

634 dissolved oxygen dynamics in an estuarine system: implications for measurement of

635 community metabolism. Estuarine and Coastal Marine Science, 11(4), 407-431.

636 Kemp, W.M. and Testa, J.M., 2011. Metabolic balance between ecosystem production

637 and consumption. Treatise on estuarine and coastal science, 7. 
638 Kemp, W.M., Boynton, W.R., Adolf, J.E., Boesch, D.F., Boicourt, W.C., Brush, G.,

639 Cornwell, J.C., Fisher, T.R., Glibert, P.M., Hagy, J.D. and Harding, L.W., 2005.

640 Eutrophication of Chesapeake Bay: historical trends and ecological interactions. Marine

641 Ecology Progress Series, 303, 1-29.

642 Kremer, J.N. and Nixon, S.W., 1978. Coastal marine ecosystem: simulation and analysis.

643 In Coastal marine ecosystem: simulation and analysis. Springer-Verlag.

644 Lake, S.J., Brush, M.J., Anderson, I.C., and Kator, H.I., 2013. Internal versus external

645 drivers of periodic hypoxia in a coastal plain tributary estuary: the York River, Virginia.

646 Marine Ecology Progress Series 492:21-39.

647 Lancelot, C. and Muylaert, K., 2011. Trends in estuarine phytoplankton ecology. In:

648 Wolanski, E., et al. (Eds.), Treatise on Estuarine and Coastal Science, Functioning

649 Ecosystems at the Land-ocean Interface, vol. 7, 5-15.

650 Lemagie, E.P. and Lerczak, J.A., 2015. A comparison of bulk estuarine turnover

651 timescales to particle tracking timescales using a model of the Yaquina Bay

652 Estuary. Estuaries and Coasts, 38(5), 1797-1814.

653 Lucas, L.V., Koseff, J.R., Monismith, S.G., Cloern, J.E. and Thompson, J.K., 1999.

654 Processes governing phytoplankton blooms in estuaries. II: The role of horizontal

655 transport. Marine Ecology Progress Series, 187, 17-30. 
656 Lucas, L.V., Sereno, D.M., Burau, J.R., Schraga, T.S., Lopez, C.B., Stacey, M.T., Parchevsky, 657 K.V. and Parchevsky, V.P., 2006. Intradaily variability of water quality in a shallow tidal 658 lagoon: mechanisms and implications. Estuaries and Coasts, 29(5), 711-730.

659 Lucas, L.V., Thompson, J.K. and Brown, L.R., 2009. Why are diverse relationships 660 observed between phytoplankton biomass and transport time. Limnology and 661 Oceanography, 54(1), 381-390.

662 Marshall, H.G. and Egerton, T.A., 2013. Assessing seasonal relationships between 663 chlorophyll a concentrations to phytoplankton composition, biomass, and abundance, 664 emphasizing the bloom producing algae (HAB and others) within the James, Elizabeth, 665 and Lafayette Rivers in Virginia.

666 Nesius, K.K., Marshall, H.G. and Egerton, T.A., 2007. Phytoplankton Productivity in the 667 Tidal Regions of Four Chesapeake Bay (USA) Tributaries. Virginia Journal of 668 Science, 58(4).

669 Odum, H.T., 1956. Primary production in flowing waters. Limnology and Oceanography, $6701(2), 102-117$.

671 Paerl, H.W., Hall, N.S., Peierls, B.L., Rossignol, K.L. and Joyner, A.R., 2014. Hydrologic 672 variability and its control of phytoplankton community structure and function in two 673 shallow, coastal, lagoonal ecosystems: the Neuse and New River Estuaries, North 674 Carolina, USA. Estuaries and Coasts,37(1), 31-45. 
675 Paerl, H.W., Valdes, L.M., Peierls, B.L., Adolf, J.E. and Harding Jr, L.W., 2006.

676 Anthropogenic and climatic influences on the eutrophication of large estuarine

677 ecosystems. Limnology and Oceanography, 51(1 part 2), 448-462.

678 Peierls, B.L., Hall, N.S. and Paerl, H.W., 2012. Non-monotonic responses of

679 phytoplankton biomass accumulation to hydrologic variability: a comparison of two

680 coastal plain North Carolina estuaries. Estuaries and Coasts, 35(6), 1376-1392.

681 Reaugh, M.L., Roman, M.R. and Stoecker, D.K., 2007. Changes in plankton community

682 structure and function in response to variable freshwater flow in two tributaries of the

683 Chesapeake Bay. Estuaries and Coasts, 30(3), 403-417.

684 Shen, J. and Lin, J., 2006. Modeling study of the influences of tide and stratification on

685 age of water in the tidal James River. Estuarine, Coastal and Shelf Science, 68(1), 101-

686112.

687 Shen, J., Wang, T., Herman, J., Mason, P. and Arnold, G.L., 2008. Hypoxia in a coastal

688 embayment of the Chesapeake Bay: A model diagnostic study of oxygen

689 dynamics. Estuaries and Coasts, 31(4), 652-663.

690 Shen, J., Wang, Y. and Sisson, M., 2016. Development of the Hydrodynamic Model for

691 Long-Term Simulation of Water Quality Processes of the Tidal James River,

692 Virginia. Journal of Marine Science and Engineering, 4(4), p.82. 
693 Staehr, P.A., Bade, D., Van de Bogert, M.C., Koch, G.R., Williamson, C., Hanson, P., Cole, 694 J.J. and Kratz, T., 2010. Lake metabolism and the diel oxygen technique: state of the 695 science. Limnology and Oceanography: Methods, 8(11), 628-644.

696 Staehr, P.A., Testa, J.M., Kemp, W.M., Cole, J.J., Sand-Jensen, K., and Smith, S.V., 2012.

697 The metabolism of aquatic ecosystems: history, applications, and future challenges.

698 Aquat. Sci. 74, 15-29.

699 Valdes-Weaver, L.M., Piehler, M.F., Pinckney, J.L., Howe, K.E., Rossignol, K. and Paerl, 700 H.W., 2006. Long - term temporal and spatial trends in phytoplankton biomass and

701 class - level taxonomic composition in the hydrologically variable Neuse - Pamlico

702 estuarine continuum, North Carolina, USA. Limnology and Oceanography, 51(3), 14107031420.

704 Wang, C.F., Hsu, M.H. and Kuo, A.Y., 2004. Residence time of the Danshuei River 705 estuary, Taiwan. Estuarine, Coastal and Shelf Science, 60(3), 381-393. 
Table 1. Estimated values for each parameter for different timescales based on analysis of three years of high-frequency continuous

707 monitoring data at Station JMS073.37 (RC) and 24 years of long-term monitoring data at Station TF5.5 (1990-2013). Results of

708 transport rate $F$ are computed from the 3D numerical model.

\begin{tabular}{|c|c|c|c|c|c|c|c|c|c|c|}
\hline \multirow{2}{*}{$\begin{array}{l}\text { Statistical parameters } \\
\text { for each timescales }\end{array}$} & \multicolumn{7}{|c|}{$\begin{array}{l}\text { Continuous Monitoring Station (JMS073.37) } \\
\qquad 2006-2008\end{array}$} & \multicolumn{3}{|c|}{$\begin{array}{l}\text { Long-term Monitoring Station (TF5.5) } \\
\qquad 1990-2013\end{array}$} \\
\hline & $\begin{array}{l}\text { Hourly } \\
(1 \mathrm{~h})\end{array}$ & $\begin{array}{c}\text { Tidal } \\
(12.5 \mathrm{~h})\end{array}$ & $\begin{array}{l}\text { Daily } \\
\text { (1 d) }\end{array}$ & $\begin{array}{c}\text { Spring-neap } \\
(14.5 \mathrm{~d})\end{array}$ & $\begin{array}{l}\text { Monthly } \\
(30 \mathrm{~d})\end{array}$ & $\begin{array}{c}\text { Seasonal } \\
(90 \mathrm{~d})\end{array}$ & $\begin{array}{l}\text { Annual } \\
\text { (365 d) }\end{array}$ & Monthly & Seasonal & Annual \\
\hline \multicolumn{11}{|l|}{ Medians of $\left(d^{-1}\right)$} \\
\hline positive $r$ & 1.3795 & 0.2437 & 0.1059 & 0.0217 & 0.0106 & 0.0047 & 0.0014 & 0.0246 & 0.0148 & 0.0042 \\
\hline negative $r$ & -1.2740 & -0.2443 & -0.1112 & -0.0245 & -0.0128 & -0.0073 & -0.0042 & -0.0213 & -0.0112 & -0.0027 \\
\hline positive $-F$ & 1.3174 & 0.1359 & 0.0564 & 0.0106 & 0.0210 & / & / & 0.0184 & / & / \\
\hline negative $-F$ & -1.1343 & -0.1481 & -0.0740 & -0.0328 & -0.0319 & -0.0391 & -0.0406 & -0.0421 & -0.0469 & -0.0479 \\
\hline positive $\mu$ & 1.3555 & 0.2987 & 0.1402 & 0.0461 & 0.0379 & 0.0379 & 0.0369 & 0.0472 & 0.0482 & 0.0496 \\
\hline negative $\mu$ & -1.3179 & -0.2779 & -0.1293 & -0.0185 & -0.0107 & / & / & -0.0161 & / & / \\
\hline \multicolumn{11}{|l|}{$\begin{array}{l}\text { Correlation of } \\
\text { determination } R^{2}\end{array}$} \\
\hline$F \sim r$ & 0.0138 & 0.0011 & 0.0071 & 0.1082 & 0.1503 & 0.4612 & 0.6106 & 0.1687 & 0.2172 & 0.4755 \\
\hline$\mu \sim r$ & 0.9226 & 0.7921 & 0.7184 & 0.2843 & 0.2148 & 0.0768 & 0.0211 & 0.5750 & 0.5137 & 0.0275 \\
\hline \multicolumn{11}{|l|}{ Relatively Importance } \\
\hline Transport & 0.2189 & 0.3148 & 0.3509 & 0.4947 & 0.5067 & 0.5207 & 0.5172 & 0.5258 & 0.5081 & 0.4910 \\
\hline Local & 0.7811 & 0.6852 & 0.6491 & 0.5053 & 0.4933 & 0.4793 & 0.4828 & 0.5485 & 0.5159 & 0.5103 \\
\hline
\end{tabular}


710 Table 2. Estimates of annual phytoplankton gross primary production (GPP), total

711 biological losses ( $R P P$, including respiration, grazing and settling), DPP (GPP - RPP), the

712 amount of production flushed out (FPP) at Station RC for the three years 2006 to 2008.

713 FPP/GPP representing the fraction of production flushed out are also presented.

\begin{tabular}{|c|c|c|c|c|c|}
\hline \multirow{2}{*}{$\begin{array}{l}\text { Annual } \\
\text { phytoplankton } \\
\text { metabolic rates }\end{array}$} & $G P P^{1}$ & $R P P^{1}$ & $D P P^{1}$ & $F P P^{2}$ & \multirow{2}{*}{$\frac{F P P}{G P P}$} \\
\hline & \multicolumn{4}{|c|}{$\left(g C m^{-2} y^{-1}\right)$} & \\
\hline 2006 & 255.90 & 274.29 & -18.39 & 32.65 & $12.76 \%$ \\
\hline 2007 & 685.91 & 688.50 & -2.59 & 47.76 & $6.96 \%$ \\
\hline 2008 & 486.26 & 512.42 & -26.16 & 31.87 & $6.55 \%$ \\
\hline \multicolumn{6}{|c|}{$\begin{array}{l}{ }^{1} \text { estimated using } 15 \text {-minute observational data } \\
{ }^{2} \text { estiatmed using numerical model }\end{array}$} \\
\hline
\end{tabular}

714 


\section{Figure Captions}

715 Fig. 1. Map of the Chesapeake Bay and James River. Locations for the Continuous

716 Monitoring Stations RC, and the Long-term Monitoring Stations TF5.4 and TF5.5 are

717 shown, respectively, by the green triangle and the blue squares. The domain of the

718 James River 3D model is also presented.

719 Fig. 2. Comparison of the 6-h moving averages of $r$ and $F$ at Station RC in October 2008.

720 a) time series of relative growth rate $r$ (red line), transport rate $F$ (blue line, here plotted

721 as $-F$ ), and irradiance (black line); b) the relation between $-F$ and $r$ using all data during

722 the month (daytime + nighttime); $c$ ) the relation between $-F$ and $r$ only at nighttime.

723 Fig. 3. Contributions of transport processes on monthly timescales at Station TF5.5. a)

724 time series of $c h l-a$ (black line, $\mu g L^{-1}$ ) and residence time (blue line); b) the relationship

725 between chl- $a$ and residence time; c) time series of relative growth rate $r$ (black line)

726 and transport rate $F$ (blue line, $-F$ ); d) the relationship between $-F$ and $r$. The data used

727 are from the years 2000 to 2013.

728 Fig. 4. Rates $r,-F$, and $\mu$ on seasonal and annual timescales during the years 1990 to

7292013 at Station TF5.5.

730 Fig. 5. Box plot for rates $r,-F$, and $\mu$ on seasonal timescale during the years 1990 to

7312013 at Station TF5.5. Horizontal lines in the boxes indicate medians, boxes indicate

732 interquartile ranges, whiskers indicate the extremes that are set to be 1.5 times the

733 range from the boxes, notches in boxes indicate the $95 \%$ confidence intervals of

734 medians, and circles indicate outliers. 
735 Fig. 6. a) Medians over different timescales for positive and negative rates, respectively.

736 Transport rate $(-F$, blue lines), relative growth rate $r$ (red lines), and growth rate

$737 \mu$ (green lines); b) Ratios of root-mean-square of rates. Blue line denotes $r m s(F)$ to

$738 r m s(r)$, green line denotes $r m s(\mu)$ to $r m s(r)$; c) coefficient of determination $\mathrm{R}^{2}$ between $F$

739 and $r$ (blue line) and between $\mu$ and $r$ (green line); and $d$ ) estimates of the relative

740 importance of transport processes (blue line) and local processes (green line).

741 Fig. 7. Phytoplankton primary production in each season of 2008 at Station RC, by

742 assuming $F P P=F \cdot B$ (winter data are not available). Phytoplankton gross primary

743 productivity $(G P P)$, phytoplankton total biological losses ( $R P P$, including respiration,

744 grazing and settling), phytoplankton DPP (GPP - RPP), error bars represent the 95\%

745 confidence intervals. 


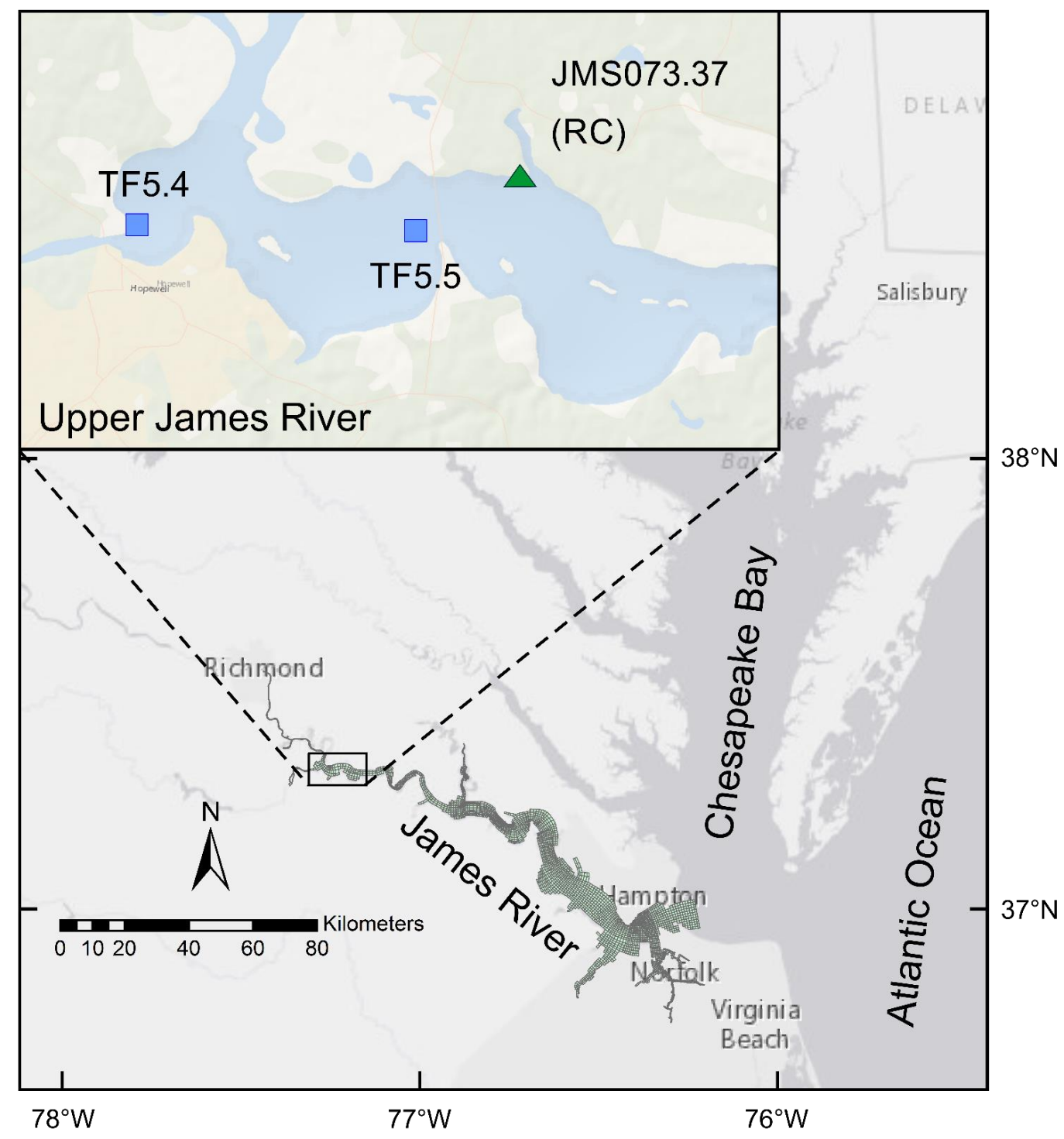

748 Fig. 1. Map of the Chesapeake Bay and James River. Locations for the Continuous

749 Monitoring Stations RC, and the Long-term Monitoring Stations TF5.4 and TF5.5 are

750 shown, respectively, by the green triangle and the blue squares. The domain of the 751 James River 3D model is also presented. 

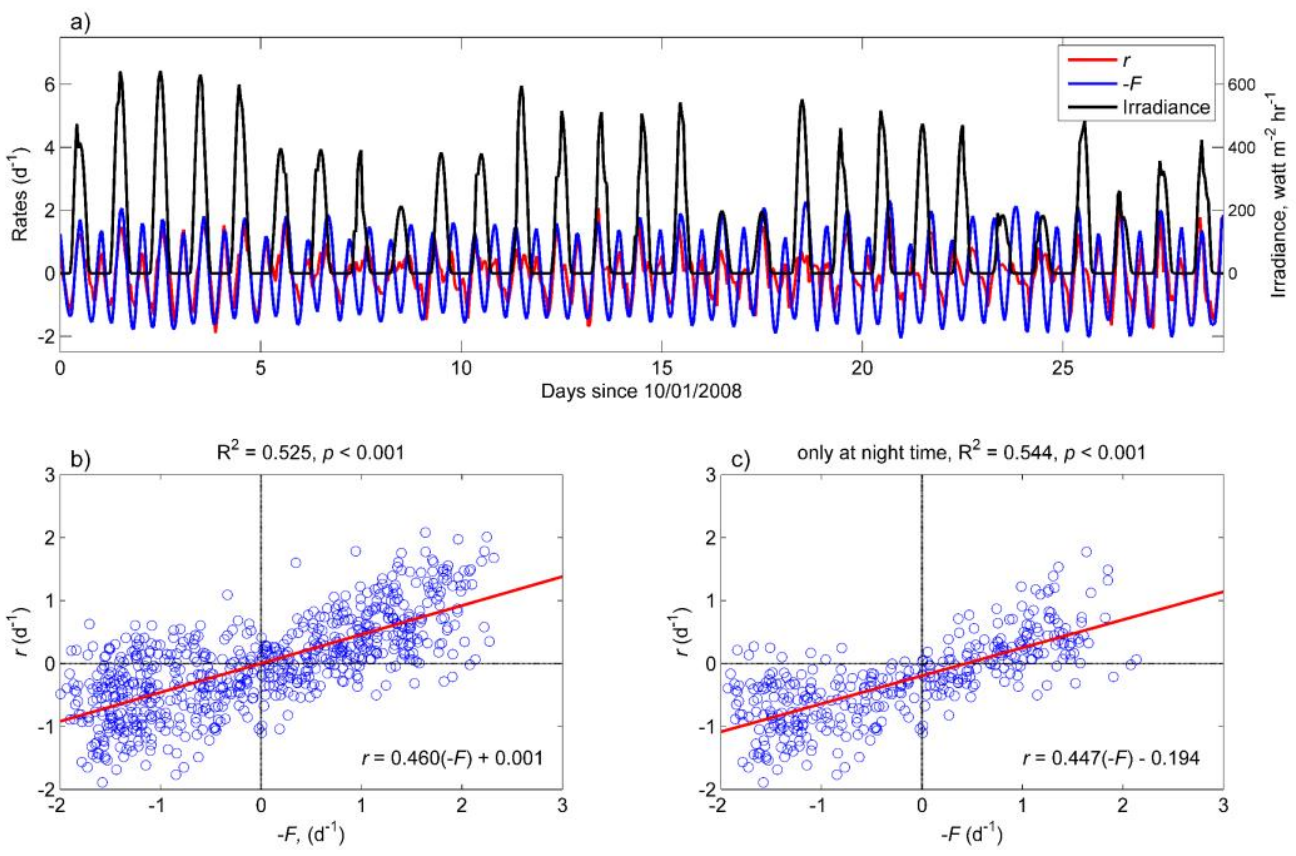

752

753 Fig. 2. Comparison of the 6-h moving averages of $r$ and $F$ at Station RC in October 2008.

754 a) time series of relative growth rate $r$ (red line), transport rate $F$ (blue line, here plotted

755 as $-F$ ), and irradiance (black line); b) the relation between $-F$ and $r$ using all data during

756 the month (daytime + nighttime); $c$ ) the relation between $-F$ and $r$ only at nighttime. 

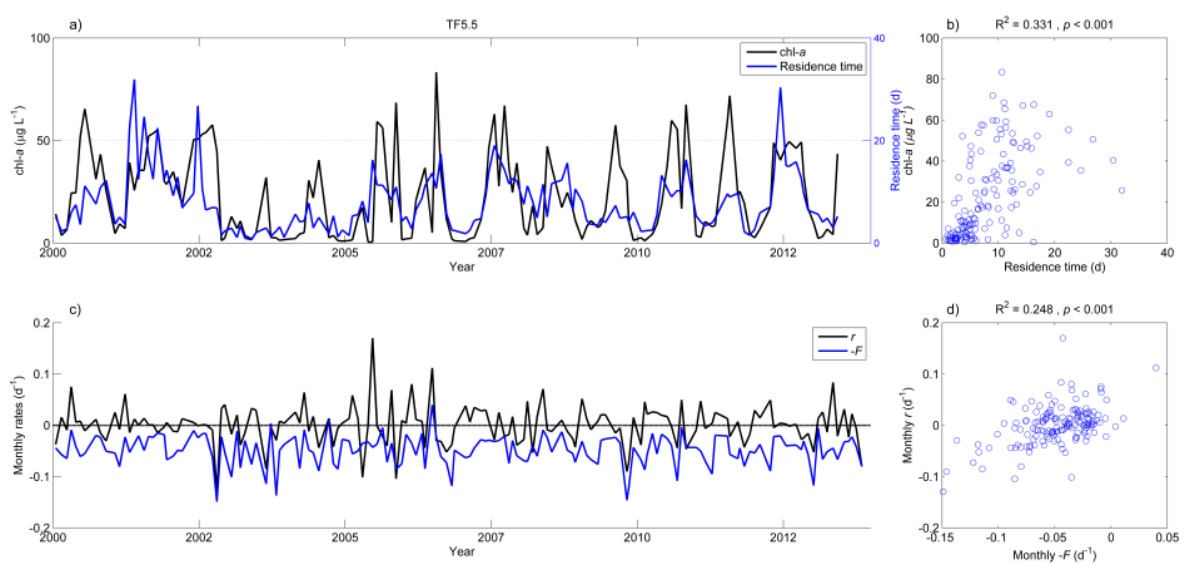

757

758 Fig. 3. Contributions of transport processes on monthly timescales at Station TF5.5. a)

759 time series of $c h l-a$ (black line, $\mu g L^{-1}$ ) and residence time (blue line); b) the relationship

760 between $c h l-a$ and residence time; c) time series of relative growth rate $r$ (black line)

761 and transport rate $F$ (blue line, $-F$ ); $d$ ) the relationship between $-F$ and $r$. The data used

762 are from the years 2000 to 2013. 

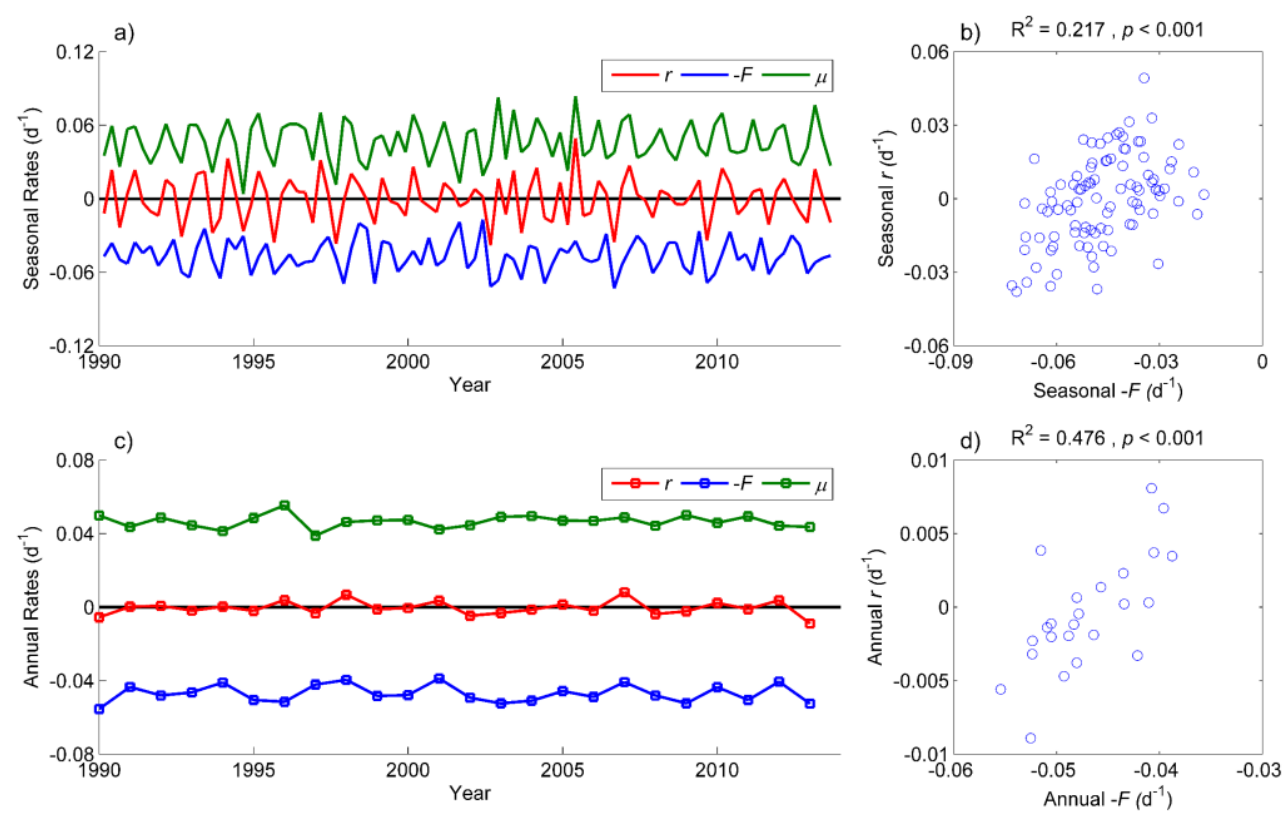

763

764 Fig. 4. Rates $r,-F$, and $\mu$ on seasonal and annual timescales during the years 1990 to

7652013 at Station TF5.5. 


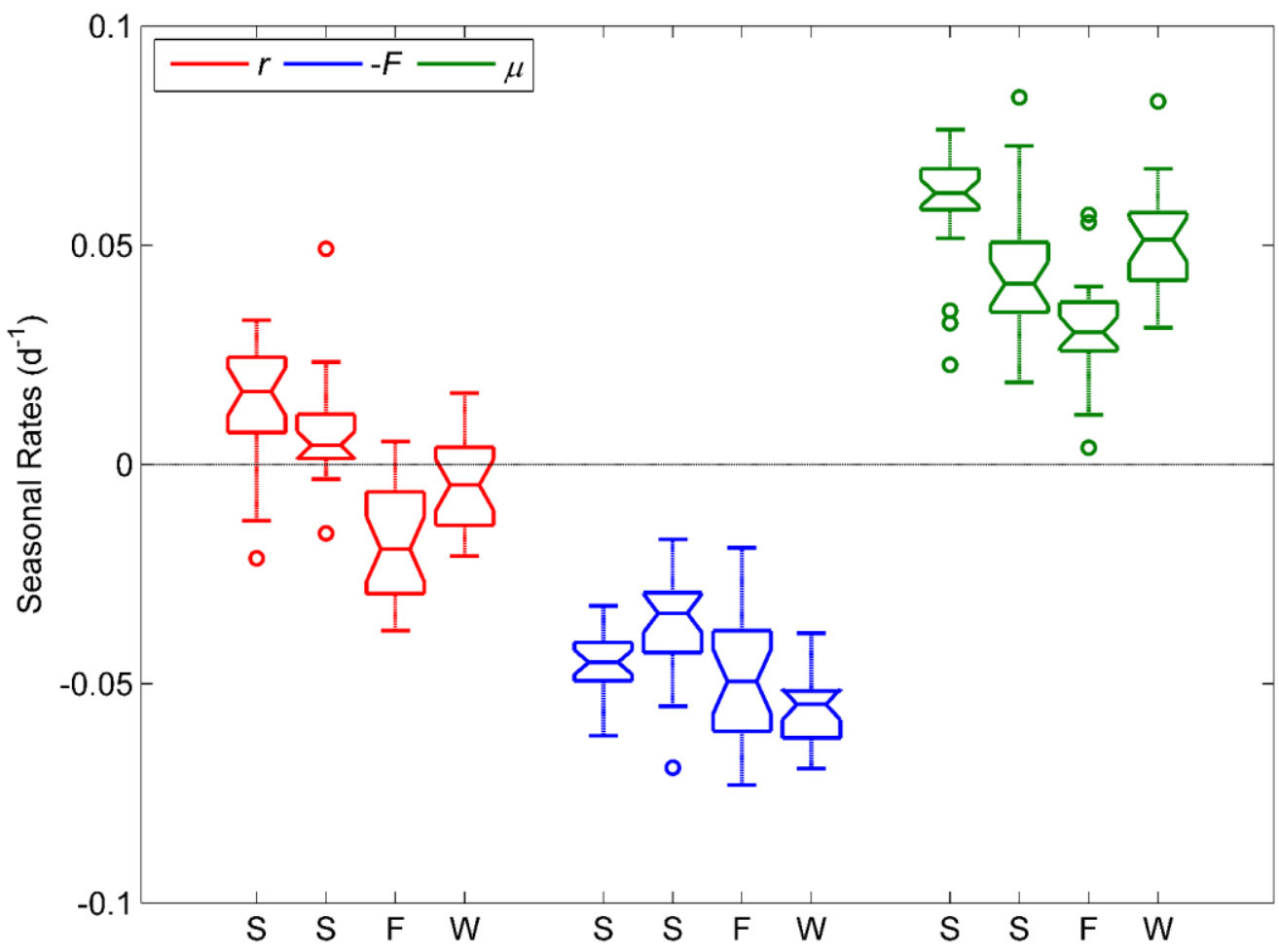

766

767 Fig. 5. Box plot for rates $r,-F$, and $\mu$ on seasonal timescale during the years 1990 to

7682013 at Station TF5.5. Horizontal lines in the boxes indicate medians, boxes indicate

769 interquartile ranges, whiskers indicate the extremes that are set to be 1.5 times the

770 range from the boxes, notches in boxes indicate the $95 \%$ confidence intervals of

771 medians, and circles indicate outliers. 

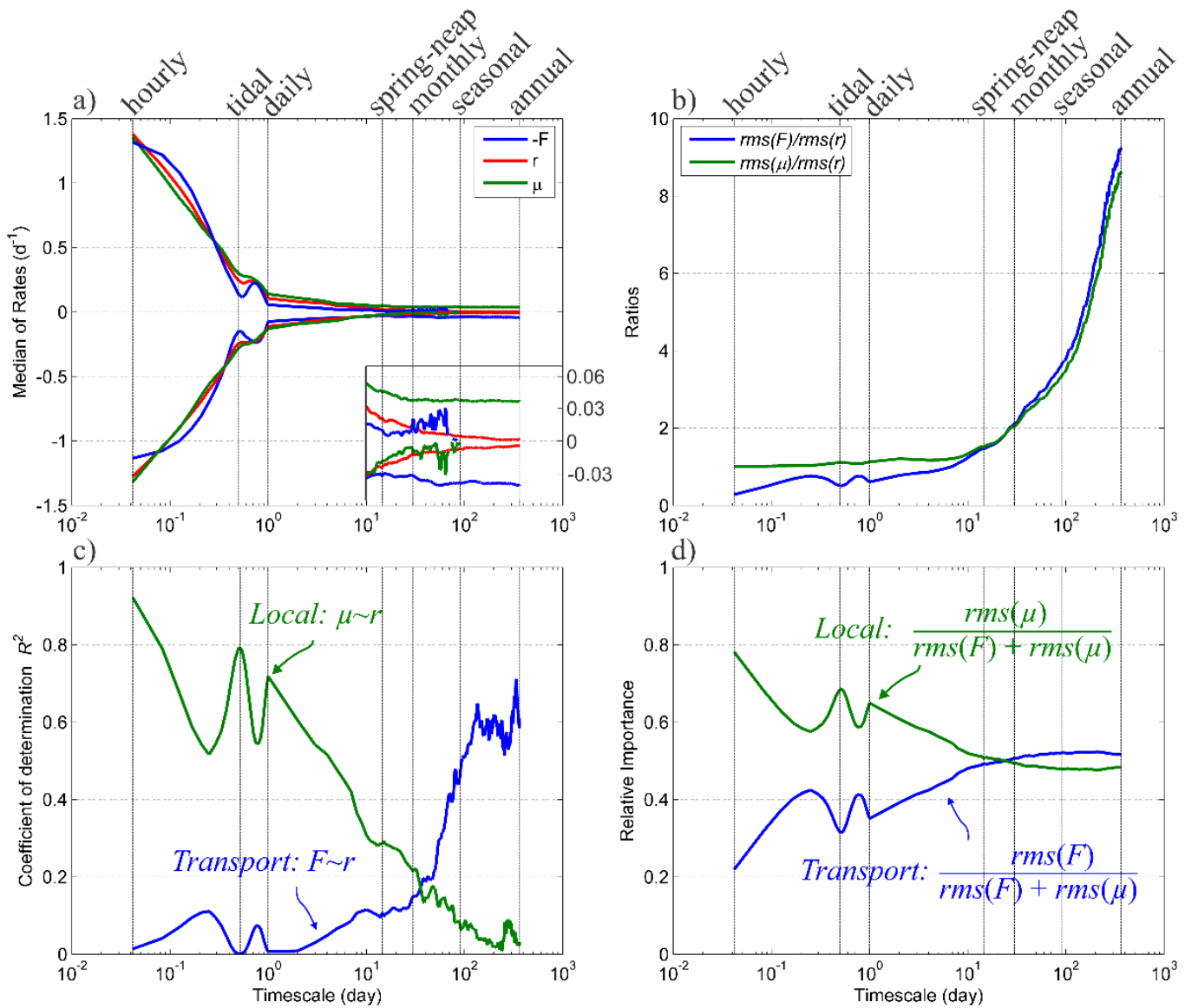

772

773 Fig. 6. a) Medians over different timescales for positive and negative rates, respectively.

774 Transport rate $(-F$, blue lines), relative growth rate $r$ (red lines), and growth rate

$775 \mu$ (green lines); b) Ratios of root-mean-square of rates. Blue line denotes $r m s(F)$ to

$776 r m s(r)$, green line denotes $r m s(\mu)$ to $r m s(r)$; c) coefficient of determination $\mathrm{R}^{2}$ between $F$

777 and $r$ (blue line) and between $\mu$ and $r$ (green line); and $d$ ) estimates of the relative

778 importance of transport processes (blue line) and local processes (green line). 


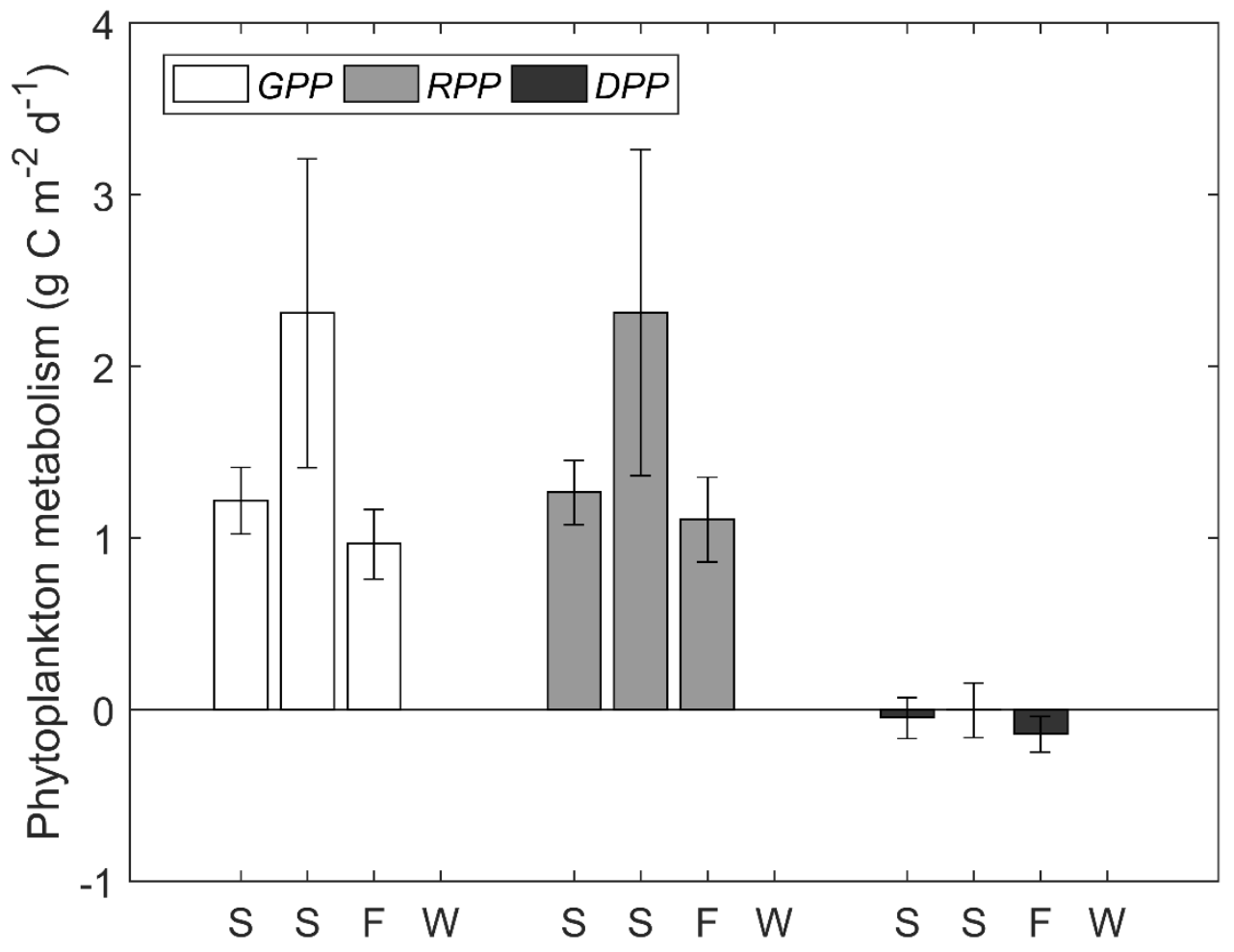

779

780 Fig. 7. Phytoplankton primary production in each season of 2008 at Station RC, by

781 assuming $F P P=F \cdot B$ (winter data are not available). Phytoplankton gross primary

782 productivity (GPP), phytoplankton total biological losses ( $R P P$, including respiration,

783 grazing and settling), phytoplankton DPP (GPP - RPP), error bars represent the 95\%

784 confidence intervals. 